\title{
A EDUCAÇÃO NO CONTEXTO DO AQUECIMENTO GLOBAL: DA IGNORÂNCIA E ANALFABETISMO CIENTÍFICO AO RACIOCÍNIO CRÍTICO E LITERACIA CLIMÁTICA
}

\author{
Marcos José de Oliveira ${ }^{1}$ \\ Francisco Arthur da Silva Vecchia ${ }^{2}$ \\ Celso Dal Re Carneiro ${ }^{3}$
}

\begin{abstract}
RESUMO
No Brasil, indicadores de educação mostram que a situação do país está entre as piores posições em rankings internacionais. A falta de qualidade educacional reflete diretamente na incapacidade do público em entender temas e conceitos científicos. Nesse contexto, as mudanças climáticas representam um tema complexo, difícil de ensinar e de compreender. Explorando o baixo grau de instrução da população em geral, em sua maioria analfabeta em temas científicos e climáticos, a mídia tem conseguido embutir um medo descabidamente exagerado nas pessoas, ao noticiar previsões de climas futuros de forma extremamente alarmista. Consequentemente, distúrbios psicológicos estão sendo relatados em pessoas apavoradas pelas notícias de aquecimento global. Para reverter esse quadro geral, a apresentação de informações com maior diversidade de visões e o incentivo do raciocínio científico e crítico pelos professores e jornalistas representam um rumo para alcançar a literacia climática.
\end{abstract}

\section{EDUCATION IN THE CONTEXT OF GLOBAL WARMING : THE IGNORANCE AND SCIENTIFIC ILLITERACY THE REASONING AND CRITICAL LITERACY CLIMATE}

\footnotetext{
ABSTRACT

In Brazil, educational indicators show that the country's situation is among the worst positions in international rankings. The lack of educational quality directly reflects the public's inability on understanding scientific concepts and issues. In this context, climate change is a complex issue, difficult

${ }^{1}$ Engenheiro Ambiental (USP), Mestre e Doutorando na área de Climatologia, no PPG em Ciências da Engenharia Ambiental (PPG-SEA), Centro de Ciências da Engenharia Aplicadas ao Meio Ambiente (CCEAMA), Escola de Engenharia de São Carlos (EESC), Universidade de São Paulo (USP). E-mail: marcos.jose@gmail.com

2 Prof Dr. do Departamento de Hidráulica e Saneamento (EESC-USP) e Diretor do CCEAMA. E-mail: fvecchia@sc.usp.br

${ }^{3}$ Prof. Dr. do Departamento de Geociências Aplicadas ao Ensino (DGAE), Instituto de Geociências (IG), Universidade Estadual de Campinas (UNICAMP). E-mail: cedrec@ige.unicamp.br
} 
to teach and to understand. Exploring the low level of education among the population, which are mostly illiterate in scientific and climate issues, the media has managed to embed an unreasonably exaggerated fear in people by reporting future climates predictions in an extremely alarmist way. Consequently, psychological disorders are being reported in people terrified by global warming news. To reverse this general framework, the presentation of information with greater diversity of views and the promotion of scientific and critical thinking by teachers and journalists represent a direction for achieve climate literacy.

\title{
EDUCACIÓN EN EL CONTEXTO DEL CALENTAMIENTO GLOBAL: LA IGNORANCIA Y LA CIENCIA ANALFABETISMO EL RAZONAMIENTO Y CLIMA ALFABETIZACIÓN CRÍTICA
}

\begin{abstract}
RESUMEN
En Brasil, los indicadores educativos muestran que la situación del país se encuentra entre las peores posiciones en los rankings internacionales. La falta de calidad de la educación se refleja directamente la incapacidad del público a entender los problemas y conceptos científicos. En este contexto, el cambio climático es un tema complejo, difícil de enseñar y entender. Explorando el bajo nivel de educación de la población, en su mayoría analfabeto en cuestiones científicas y climáticas, los medios de comunicación han logrado insertar un miedo injustificado exagerado en las personas, a través de noticias con predicciones muy alarmistas de climas futuros. En consecuencia, los trastornos psicológicos están siendo reportados en personas aterrorizadas por la noticia del calentamiento global. Para revertir este marco general, la presentación de información con mayor diversidad de puntos de vista y la promoción del pensamiento científico y crítico por los profesores y periodistas representan una forma de lograr la alfabetización climática.
\end{abstract}

PALAVRAS-CHAVE: ensino e educação, mudanças climáticas, aquecimento global, climatologia

\section{INTRODUÇÃO}

Em plena era da informação, o amplo acesso a imensa quantidade de informações tem, por um lado, permitido ao público um avanço imensurável em termos de conhecimento adquirido, mas, por outro lado, ainda persiste na população em geral muita confusão sobre conceitos científicos bastante básicos. Quando o assunto em voga é a mudança climática e o aquecimento global, o déficit educacional e o consequente baixo nível de alfabetização científica conduz a diversos malentendidos.

Aliado à baixa capacidade de entendimento que público tem a respeito de conceitos relacionados ao clima, o tom alarmista das mudanças climáticas propagado pela mídia tem contribuído com a crescente preocupação da população. No contexto da discussão das causas e efeitos do recente aquecimento global, a falta de conhecimento (ignorância) tem gerado um medo descabido, o qual tem afligido as pessoas e provocado diferentes níveis de ansiedade, chegando, inclusive até ao 
desespero extremo de pais cometerem o homicídio dos próprios filhos e depois se suicidarem.

No campo da educação formal e informal, transformar a ignorância e analfabetismo científico em literacia científica e climática dependem essencialmente dos professores e dos jornalistas, cujas incumbências são cruciais no ensino crítico da ciência, não somente fornecendo um conhecimento preciso e adequado, mas também estimulando e favorecendo uma visão crítica, fundamentada no raciocínio científico.

\section{BREVE PANORAMA DA EDUCAÇÃO NO BRASIL}

Dados do Programa Internacional de Avaliação de Estudantes (PISA, sigla do inglês), da Organização para Cooperação e Desenvolvimento Econômico (OCDE) aponta o péssimo desempenho dos jovens estudantes brasileiros com 15 anos de idade. O último teste, realizado em 2012, aplicou provas em 65 países do mundo para mais de 500 mil alunos, os quais tiveram suas habilidades e conhecimentos analisados no campo da leitura, matemática e ciências (OCDE, 2015). Ainda que tenha melhorado em relação às avaliações trienais anteriores (OCDE, 2013), os resultados da avaliação do Brasil no PISA colocam o país entre as piores posições no

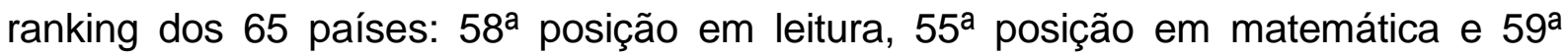
posição em ciências. (OCDE, 2014).

A avaliação de 2006 do PISA enfatizou perguntas sobre ciência e, além disso, os alunos responderam a testes relacionados ao meio ambiente. Assim, os resultados dessa avaliação (OCDE, 2009) permitem analisar o desempenho nos campos das ciências ambientais e das geociências. A proficiência nessas duas áreas do conhecimento foi avaliada em quatro níveis, do "Nível $A^{* 4}$ (alunos com maior proficiência) até o "Nível $D^{\prime \prime}$ (alunos com proficiência muito básica). Alguns alunos não mostraram qualquer proficiência mensurável e ficaram, portanto, abaixo do "Nível D”. No cômputo geral da proficiência de todos os países avaliados, cerca de $19 \%$ dos alunos foram classificados como proficientes no "Nível A" em ciências ambientais e

\footnotetext{
${ }^{4}$ Estudantes no "Nível A" são capazes de explicar minuciosamente os processos e fenômenos ambientais. Eles demonstram uma capacidade de comparar e diferenciar entre explicações divergentes, examinando evidências de apoio conciliadas ao seu conhecimento. Eles são capazes de sintetizar respostas de fontes múltiplas.

5 Estudantes com nota abaixo do "Nível D" são incapazes de demonstrar competências científicas em situações exigidas nos testes mais fáceis do PISA. Os estudantes neste nível não são capazes de interpretar informações a partir de um gráfico ou uma figura, bem como são incapazes de mostrar conhecimento básico de processos ambientais comuns. Por exemplo, eles não conseguem descrever as diferenças e semelhanças entre certos parâmetros ambientais, ou fornecer informação histórica adequada e completa, ou extrair relações causais entre processos ambientais que ocorrem em momentos diferentes.
} 
$14 \%$ em geociências. Os alunos receberam pontuação pela sua capacidade em três competências em ciências (identificação de questões científicas, explicação científica de fenômenos e utilização de evidências científicas).

De um total de 57 países avaliados no PISA 2006 (OCDE, 2009), os resultados mostram que o Brasil ficou classificado, respectivamente, nas áreas de ciências ambientais e das geociências, na 54 posição (na frente somente de Azerbaijão, Quirguistão e Catar) e na 53a posição (na frente de Tunísia, Azerbaijão, Quirguistão e Catar). Nas ciências ambientais, apenas $5 \%$ dos estudantes brasileiros obtiveram classificação no "Nível A" e cerca de 37\% abaixo do "Nível D". Para comparar, a Finlândia ( $1^{\text {a }}$ no ranking) teve, inversamente, $31 \%$ dos alunos situados no "Nível A" e 6\% abaixo do "Nível D". Com relação às geociências, os números indicam praticamente a mesma situação: o Brasil teve 5\% no "Nível A" e 35\% abaixo do "Nível D"; a Finlândia obteve $25 \%$ no "Nível A" e $6 \%$ abaixo do "Nível D". Ressalta-se que os estudantes com proficiência abaixo do "Nível D" possuem muita dificuldade em responder às perguntas que contêm informações científicas relevantes para problemas ou fenômenos ambientais elementares.

\section{LITERACIA CIENTÍFICA}

A ciência, a matemática e a tecnologia têm um profundo impacto em nossas vidas individuais e em nossa cultura. Elas desempenham um papel em quase todas as atividades humanas, afetando a maneira como nos relacionamos uns com os outros e com o mundo ao nosso redor. A literacia científica permite-nos oferecer sentido aos fenômenos do mundo real, subsidia nossas decisões pessoais e sociais, e serve como uma base para uma vida de aprendizagem. Um cidadão cientificamente alfabetizado possui a habilidade de encontrar a informação científica, pensar e avaliar criticamente as informações e apresentar uma opinião ou decisão (USGCRP, 2009).

Em alguns países e regiões do mundo, o nível de conhecimento e entendimento de conceitos científicos pela população em geral - definido como alfabetização, letramento ou literacia científica ${ }^{6}$ - tem sido medido por meio de pesquisas de opinião (enquetes). Os resultados dessas enquetes são surpreendentes: nos EUA e no Reino Unido, em pesquisa realizada em 1988, perguntou-se aos

\footnotetext{
${ }^{6}$ A importância da literacia científica e do pensamento crítico na educação é abordado por Anelli (2011) e Tenreiro-Vieira e Vieira (2013).
} 
entrevistados: "a Terra gira ao redor do Sol, ou o Sol gira em torno da Terra?". Aos que acertavam a resposta, adicionalmente perguntou-se: "a Terra gira em torno do Sol uma vez por dia, uma vez por mês ou uma vez por ano?”. Apenas cerca de $47 \%$ dos norte-americanos e $33 \%$ dos britânicos entrevistados informaram corretamente que a Terra se move em torno do Sol uma vez a cada ano. Em novas pesquisas, entrevistou-se, em 1995, em torno de 2.000 adultos nos EUA, e cerca de 12.000 pessoas na União Europeia, em 1992. Resultados: somente 47\% dos americanos e $51 \%$ dos europeus acertaram essa questão sobre um conceito científico relativamente simples. (MILLER, 1998).

Dados mais atuais indicam uma melhoria do nível de literacia científica da população, todavia, ainda assim a situação continua preocupante. Os Indicadores de Ciência e Engenharia, publicado em 2014 pelo Conselho Nacional de Ciência dos EUA (NATIONAL SCIENCE BOARD, 2014, p. 7-23), revelou que, dos entrevistados perguntados sobre se a Terra girava em torno do Sol, estavam corretos $74 \%$ dos norte-americanos (em 2012), 66\% dos europeus (em 2005), 70\% dos indianos (em 2005), $72 \%$ dos malásios (em 2008) e 86\% dos sul-coreanos (em 2004). Na média desses países, constata-se que, a cada 4 pessoas, 1 desconhece o movimento de translação da Terra.

No Brasil, a avaliação da literacia científica carece de estudos exatamente nos moldes das perguntas ${ }^{7}$ realizadas no âmbito dos Indicadores de Ciência e Engenharia dos EUA. Ainda assim, o Ministério da Ciência, Tecnologia e Inovação, conduziram duas enquetes nacionais sobre a "Percepção pública da ciência e tecnologia no Brasil”, uma em 2007 (BRASIL, 2007) e outra em 2010 (BRASIL, 2010). A publicação mais atual relata os resultados de entrevistas realizadas com cerca de 2.000 brasileiros adultos (com mais de 16 anos), com o intuito de levantar o interesse, o grau de informação, as atitudes, as visões e o conhecimento relativos à Ciência e Tecnologia (C\&T).

Para testar o nível de literacia científica dos brasileiros, tão-somente duas perguntas foram realizadas no âmbito da publicação de 2010: "Você conhece alguma instituição que se dedique a fazer pesquisa científica em nosso país?" e "Você conhece algum cientista brasileiro importante?". As respostas afirmativas foram, respectivamente, $18 \%$ e $12 \%$. Dito de outra forma: 4 a cada 5 brasileiros não

${ }^{7}$ Conforme as 10 perguntas que constam na Tabela 7-8, p. 7-23 de National Science Board (2014). 
souberam sequer citar uma única instituição de pesquisa e tampouco o nome de somente um cientista renomado. Como bem observa Castelfranchi et al. (2013), tais perguntas não são suficientes para determinar o grau de conhecimento científico de uma pessoa, entretanto, são indicadores do hábito informativo e do grau de contato com notícias e informações sobre a C\&T no país. Mesmo assim, os resultados são consequências de uma triste realidade da situação educacional brasileira.

\subsection{Temas de interesse científico}

Os mesmos Indicadores de Ciência e Engenharia (NATIONAL SCIENCE BOARD, 2014, p. 7-11) apresentaram estatísticas dos principais temas de interesse do público norte-americano. As porcentagens das pessoas que disseram acompanhar atentamente a notícias relacionadas aos respectivos temas foram: condições do tempo $48 \%)$, crime (28\%), educação $(23 \%)$, meio ambiente $(21 \%)$, política $(21 \%)$, esportes (20\%), saúde (20\%), religião (17\%), economia (16\%), assuntos internacionais (16\%), ciência e tecnologia (13\%), cultura e arte $(11 \%)$, entretenimento $(10 \%)$, celebridades (7\%) e viagens (6\%). Portanto, infere-se que, diretamente ligado ao clima, o tempo (meteorológico) é o principal tema de interesse nos EUA.

Segundo Brasil (2010), os temas de maior interesse dos brasileiros são (em termos de porcentagens dos entrevistados que disseram ter "muito interesse" por cada tema): meio ambiente (46\%), medicina e saúde (42\%), religião (42\%), esportes (36\%), economia (33\%), ciência e tecnologia (30\%), arte e cultura (26\%), moda (21\%) e política (9\%). Para quem era pouco ou nada interessado em C\&T, as razões da falta de interesse indicadas foram: não entende (37\%), nunca pensou sobre isso (20\%), não tem tempo (18\%), não gosta (10\%), não liga (10\%), não precisa saber sobre isso (4\%) e não respondeu/outros (1\%).

Os meios de informação mais utilizados pelos brasileiros para se informar sobre C\&T são (em termos de porcentagens dos entrevistados que disseram utilizar "com muita frequência" o respectivo tema): TV (19\%), jornais (14\%), revistas (13\%), internet (13\%), conversa com amigos (11\%), livros (10\%) e rádio (5\%). (BRASIL, 2010).

Sobretudo a partir da década de 1990, as mudanças climáticas tornaram-se uma questão ambiental central para o público nacional e mundial. Em pesquisas de opinião sobre o "aquecimento global" em 1989, descobriu-se que $63 \%$ dos norte- 
americanos "se preocupavam muito" com o assunto. (NATIONAL SCIENCE BOARD, 2014, p. 7.40). Os dados mais recentes, de 2013, internacionalmente comparáveis e representativos da opinião pública sobre as mudanças climáticas, indicam que os EUA estão entre os países com a menor preocupação sobre a mudança climática, configurando na 34a posição de um ranking de 40 países pesquisados. Nessa pesquisa, cerca de $40 \%$ dos norte-americanos acreditam que as mudanças climáticas representam uma grande ameaça. Já o Brasil consta como o terceiro país mais preocupado com a questão, com $76 \%$ das pessoas acreditando em graves ameaças das mudanças do clima. (PEW RESEARCH CENTER, 2013). Para os brasileiros, as "mudanças climáticas" representam a $3^{a}$ maior área de importância para o desenvolvimento do país, ficando atrás somente das áreas de medicamentos e agricultura. (BRASIL, 2010).

\section{LITERACIA CLIMÁTICA}

A literacia climática, como parte da literacia científica, é a compreensão básica do sistema climático, incluindo os fatores naturais e antropogênicos que o afetam. Indivíduos alfabetizados na ciência do clima entendem a importância das observações, dos registos climáticos e das modelagens na interpretação do clima. Conscientes da relação fundamental entre o clima e a vida humana, os indivíduos letrados têm a capacidade de avaliar a validade dos argumentos científicos sobre o clima e usar essa informação para apoiar suas convicções e decisões.

\subsection{Analfabetismo climático}

O baixa literacia climática, ou analfabetismo climático, implica em confusões, equívocos, teorias ingênuas, crenças e percepções distorcidas que conflitam com explicações científicas aceitas. Atingindo jovens e adultos, a ignorância e os conceitos equivocados sobre numerosos aspectos das mudanças climáticas são especialmente generalizados em parte devido a uma abundância de informações complexas, divergentes, imprecisas ou mesmo com erros absurdos que vão sendo propagados.

A ciência climática inclui tópicos complicados (por exemplo, a interação entre climas nas escalas locais, regionais e global) que estão associados com termos em grande parte desconhecidos (forçamentos radiativos, aerossóis etc.), tornando desafiador atingir a alfabetização climática. O tema geralmente é difícil para a maioria 


\section{Periódico Eletrôntico

dos leigos compreender porque envolve uma esfera temporal que não é diretamente percebida. Além disso, muitas pessoas têm ideias erradas sobre as alterações climáticas. A natureza das alterações climáticas como um perigo elusivo altamente complexo e global torna difícil de identificar, entender e dominar e, muito menos, de explicar sucintamente.

São inúmeras as confusões sobre os conceitos envolvidos no tema de mudanças climáticas. Frequentemente as pessoas acreditam: que clima e tempo (meteorológico) são o mesmo conceito; que a poluição do ar causa mudanças climáticas e aquecimento global; que a destruição da camada de ozônio causa mudanças climáticas (existe uma ideia errônea de que o buraco de ozônio permite que mais energia solar ou radiação ultravioleta chegue à Terra, causando o aquecimento global); que as mudanças climáticas são causadas devido a Terra estar se aproximando do Sol; que os seres humanos são a única causa do aquecimento global; que o único gás de efeito estufa (GEE) emitido pelas atividades humanas é o dióxido de carbono $\left(\mathrm{CO}_{2}\right)$, oriundo da queima de combustíveis fósseis; que o $\left(\mathrm{CO}_{2}\right)$ não é um GEE; que o $\mathrm{CO}_{2}$ é um poluente do ar; que não existem outros GEEs além do $\mathrm{CO}_{2}$, como o vapor d'água $\left(\mathrm{H}_{2} \mathrm{O}_{(\mathrm{g})}\right)$, o metano $\left(\mathrm{CH}_{4}\right)$ e o óxido nitroso $\left(\mathrm{N}_{2} \mathrm{O}\right)$; que o $\mathrm{CO}_{2}$ é o principal GEE da atmosfera (sendo que na verdade é o vapor d'água); que efeito estufa é algo ruim e vai, eventualmente, causar a morte de todos os seres vivos; que o efeito estufa e o aquecimento global são exatamente o mesmo fenômeno; que o derretimento do gelo flutuante resultará em inundações catastróficas das áreas costeiras (SHEPARDSON et al., 2011; THEISSEN, 2011).

No caso de alunos de ensino médio, Shepardson et al. (2011) relata que aqueles que sabem um pouco mais sobre o efeito de estufa, a compreensão é bastante simplista. Para a maior parte, eles não fazem qualquer distinção entre ou confundem os tipos de radiação solar, geralmente referindo a radiação solar como "raios ultravioletas", "raios solares", "raios de sol", "calor" e "raios de calor". Além disso, muitos desconhecem que a Terra emite radiação (na região do infravermelho) e, logo, também não sabem diferenciar a radiação solar da radiação terrestre.

O panorama geral comprova que, de fato, a literacia da sociedade em torno do clima é extremamente baixa. Concordando com Somerville (2011), a ignorância pública generalizada de explicações científicas sobre os fundamentos das mudanças climáticas ilustra um fracasso educacional extremamente sério. E essa ignorância 
gera medo.

\section{A IGNORÂNCIA E O MEDO}

O medo é uma emoção que pode ser gerada pelo pensamento sobre coisas ruins que podem acontecer no futuro. Pode também ser entendido por um estado de coisas que é experimentado como perigoso e ameaçador. Aqui, refere-se a um medo mais modesto, relacionado a uma cultura de medo no qual os meios de comunicação desempenham um papel crucial nas histórias assustadoras diariamente apresentadas com foco em ameaças e riscos.

\subsection{Catastrofismo climático e medo}

O discurso do medo tem sido preponderante no debate público desde que a mudança climática tornou-se uma questão política saliente no final de 1980. (ASAYAMA, 2015). Desde então, tornaram-se comuns os termos "catástrofe climática" e "medo" do clima no futuro.

Considerando a complexidade peculiar do tema, é difícil para a maioria das pessoas compreender aspectos temporais (de longo prazo) que não são diretamente sentidas no momento (nem sempre visível). Assim, a abordagem e a percepção do assunto são socialmente construídas pela forma como se imagina o futuro, aproveitando-se do forte apelo emocional que as notícias ameaçadoras do clima exercem sobre as pessoas.

O temor das mudanças climáticas antropogênicas é baseado em suposições, ou seja, em resultados de modelos e suas previsões sobre o futuro. Os cientistas muitas vezes apresentam seus resultados ao público não-cientista em termos de impactos potenciais. As mensagens podem ser consideradas descrições frias e imparciais de resultados de modelos, mas visto em termos psicológicos, elas essencialmente evocam o medo. (STERN, 2012). Assim, o catastrofismo climático e o medo do clima futuro dominam o discurso público e constituem a maneira predominante como as pessoas reagem às mudanças climáticas: preocupadas, amedrontadas, apavoradas e até mesmo desesperadas, em alguns casos extremos.

Com o uso de uma linguagem alarmista e exagerada, o discurso do medo sobre o clima futuro criou na população a imaginação apocalíptica dos impactos catastróficos das alterações climáticas - como o aumento do nível do mar e furacões 
mortais, entre outros. Exemplificando, Dörries (2010) elenca as semânticas atuais do medo da mudança climática, as quais incluem analogias com: a guerra ("bombarelógio ecológica", "guerra contra o aquecimento global"), avisos da iminência e irreversibilidade da catástrofe ("ponto crítico", "ponto de ebulição"), cenários futuros terríveis (simbolizadas por termos como "colapso de plataformas de gelo", "derretimento da camada de gelo da Groenlândia", "liberação de hidratos de metano na tundra", "ruptura da circulação termohalina dos oceanos"), além de representações visuais onipresentes. A exemplo desta última, destaca-se uma capa da Revista Veja (edição 1961, de 21/jun/2006), onde em destaque, se lê: "Aquecimento global - Os sinais do Apocalipse: o degelo dos polos nunca foi tão violento; ciclones agora açoitam o Brasil; os desertos avançam rapidamente; e o nível dos oceanos ameaça cidades". Ao fundo do texto, uma foto (de um mar imenso e de um urso polar em cima de um pequeno pedaço de gelo) possui como legenda: "Urso-polar: o primeiro a ver seu mundo se dissolver".

\subsection{Mídia alarmista}

Uma vez que o público em geral se baseia nos meios de comunicação para entender as questões científicas, os meios de comunicação desempenham um papel importante na elaboração dessas questões ao público. Segundo Li (2014), as pessoas não vão processar uma mensagem se eles percebem que a mensagem possui pouca importância em suas vidas ou se contém um baixo grau de ameaça. Assim, é necessário um alto grau de ameaça para motivar os destinatários a responder adequadamente às mensagens apelativas de medo. Dessa forma, a mídia tem ancorado a mudança climática antropogênica em emoções apavorantes ao repetidamente classificá-la como "ameaça climática" ou "catástrofe" nas manchetes, concentrando-se também em consequências terríveis.

Os apelos de medo no domínio público predominam com uma linguagem de alarmismo que aparece em diferentes formas. Schulte (2008) destaca algumas manchetes altamente assustadoras: "A mudança climática - o novo bioterrorismo", "A mudança climática é provável de ser mortal, diz relatório das Nações Unidas", "A mudança climática induzida pelo homem, ameaça os ecossistemas e a saúde humana em uma escala global", "A mudança climática é suscetível de afetar a saúde de milhões, adverte relatório". 
Outro mecanismo utilizado para ancorar emocionalmente a mudança climática no medo tem sido o uso de metáforas de doença grave e morte ${ }^{8}$ : "Ver a nossa Terra morrer", "Estas são as imagens de satélite da Terra que revelam o quão doente o nosso planeta está", "A ameaça climática está matando a raposa do ártico", "O calor causará extinção de animais. $O$ aumento das temperaturas ameaça a vida animal de todo o planeta". (HÖIJER, 2010).

Mas por que é tão prevalente o medo nas comunicações de mudanças climáticas? O alarmismo muitas vezes não resulta da ciência da mudança climática. A mediação de mensagens de medo é ilustrado por Hulme (2007). Este autor realizou um estudo sobre a cobertura da divulgação de um relatório do Painel Intergovernamental sobre Mudanças Climáticas (IPCC, sigla do inglês) em 10 grandes jornais nacionais do Reino Unido. Apenas um jornal não publicou uma matéria sobre o relatório do IPCC. Os outros nove pulicaram artigos com manchetes de primeira página transmitindo uma mensagem de crescente ansiedade: "Aviso final", "Pior do que pensávamos", "Novos temores sobre o clima eleva o calor entre os líderes" e "Só o homem pode parar o desastre climático", além de introduzirem adjetivos como "catastrófico", "chocante", "aterrorizante" ou "devastador". Contudo, nenhuma dessas palavras estavam presentes no documento original do IPCC. Segundo O'neill e Nicholson-Cole (2009), uma possível explicação é que a noticiabilidade aumenta se os eventos poderem ser associados a uma ameaça real para a vida humana e, com o intuito de fazer isso, níveis de alarme são frequentemente ampliados. Para atrair a atenção, são bem sucedidas as características que incluem a curiosidade, o inesperado, a credibilidade, a relevância pessoal, o exagero, o realismo, o sensacionalismo e o choque.

Ativistas, imprensa, políticos e alguns cientistas parecem estar apelando ao medo para gerar uma sensação de urgência. Mas o medo gerado no público pode ter efeitos colaterais indesejáveis, afetando a saúde psicológica de certos indivíduos.

\subsection{Doenças debilitantes}

A diversidade e complexidade das ciências e os relatos midiáticos sobre o aquecimento global provocam respostas emocionais carregadas de desespero,

\footnotetext{
${ }^{8}$ A morte, a mudança e o futuro são considerados os três grandes medos da humanidade, conforme afirma Felício e Onça (2010). Nesse trabalho, é apresentada uma análise interessante no contexto do aquecimento global, as mudanças climáticas e o caos ambiental, sob a ótica da "Teoria da Tríade", proposta pelos autores.
} 
sentimentos de ansiedade, tristeza, confusão, choque, raiva, culpa, frustração, medo e desesperança (GILLESPIE, 2013). Mesmo na ausência de impactos diretos, a percepção e o medo da mudança climática podem efetivamente afetar a saúde mental. Para Fritze et al. (2008), o aumento da conscientização sobre as mudanças climáticas tem conduzido a reações emocionais negativas em determinados indivíduos.

Segundo DOHERTY e CLAYTON (2011), relatos na mídia de "eco-ansiedade" sobre a mudança climática descrevem sintomas como ataques de pânico, perda de apetite, irritabilidade, fraqueza e insônia. Mesmo na literatura científica, médicos confirmam e relatam que cada vez mais pacientes com sintomas de ansiedade e depressão estão citando as notícias sobre mudança climáticas como algo que eles estão tendo dificuldade de lidar, e que isso provoca sofrimento ou interfere na vida cotidiana.

Em um estudo com 275 adultos australianos, Gow (2010) revelou claras associações entre a angústia gerada pelas mudanças climáticas e certas distúrbios psicológicos. O público, cada vez mais preocupado com as alterações climáticas, tem sintomas que são "indicativos de depressão, ansiedade e estresse". O autor também observou que a maioria dos participantes do estudo estavam mais preocupados com a mudança climática agora do que há três, cinco e dez anos atrás, refletindo a crescente preocupação mostrada nos meios de comunicação, bem como os discursos relacionadas ao medo, perigo e catástrofe. Além disso, constatou-se que pacientes de todas as idades sentem-se igualmente indefesos, desesperados e impotentes, mas que os mais jovens possuem maior angústia geral entre os grupos etários, refletindo a tendência crescente do ensino de temas de mudança climática nos currículos escolares.

Oliveira (2010, p. 317) sintetiza que, na divulgação de notícias sobre mudanças climáticas, a mídia possui "(...) um tom predominantemente pessimista, apimentado com um sensacionalismo alarmista e catastrofista, algumas vezes até mesmo apocalíptico, com o propósito de chocar, amedrontar e apavorar a pessoas".

Um resultado extremo do pânico e desespero climático foi divulgado em 02/03/2010, em notícia intitulada "Pais atiram em bebê por desespero ante o aquecimento global" (ESTADÃO ONLINE, 2010). Neste triste episódio, uma bebê de sete meses, baleada no peito pelos próprios pais, sobreviveu depois de permanecer 
sozinha por três dias, até ser encontrada pela polícia, na cidade de Goya, norte da Argentina. Os pais teriam firmado um pacto de suicídio por temerem os efeitos do aquecimento global. Assim, eles mataram a tiros o filho de dois anos, balearam a filha de sete meses e depois se suicidaram. Sobre uma mesa na casa foi encontrada uma carta em que os pais expressavam seu nervosismo diante da falta de ações dos países contra a crise ambiental. A bebê só foi encontrada depois de os vizinhos desconfiarem do cheiro que exalava da casa e notificarem a polícia. Esse lamentável fato teve grande repercussão em blogs, onde então ficou conhecido como "aquecimenticídio" (ou warmcide, do inglês). O caso representa um dos piores efeitos colaterais do medo provocado pelo "terrorismo climático", totalmente infundado, pregado pela mídia.

\subsection{Controvérsias e ceticismo climático}

Além da elevada complexidade dos conceitos envolvidos, diferentes visões e explicações controversas aumentam ainda mais a dificuldade de uma pessoa em conseguir discernir quais informações estão corretas ou erradas no campo das mudanças climáticas.

Apesar de um alegado consenso científico quanto à expressiva contribuição humana no aquecimento global, diversos pontos polêmicos são constantemente apontados por cientistas e estudiosos - denominados céticos - que são contrários à hipótese do aquecimento global causado predominante ou exclusivamente pelo homem $^{9}$. A ciência das mudanças climáticas apresenta divergências de opiniões, com a persistência de inúmeras incertezas científicas, atreladas ao fato de haver uma forte disputa de interesses econômicos e políticos ${ }^{10}$.

Em estudo sobre a forma do tratamento midiático em relação aos discursos produzidos acerca do aquecimento global em jornais ("Folha de São Paulo" e "O Estado de São Paulo") e também de revistas semanais ("VEJA" e "ÉPOCA"), Zangalli Junior e Sant'anna Neto (2011) concluíram que o debate científico limita-se apenas a

\footnotetext{
${ }^{9}$ Para os interessados em se aprofundar nas polêmicas das mudanças climáticas, recomenda-se, como leitura complementar, as publicações acadêmicas (teses e dissertações) de Onça (2007), Oliveira (2010) e Onça (2011), os livros de Maruyama (2009), Lino (2010) e Baptista (2009), bem como o recente artigo de Felício (2014).

${ }^{10}$ As inevitáveis controvérsias em torno de discussão do grau de contribuição humana nas mudanças climáticas são frutos da disputa de diferentes interesses nas esferas científica, política, econômica, jornalística e midiática, aspectos discutidos em Oliveira e Vecchia (2009) e mais profundamente no "Capítulo 7 - Implicações e repercussões no contexto da interação entre Ciência, Mídia, Política e Economia" de Oliveira (2010).
} 
um lado da questão, ou seja, o aquecimento global foi abordado como uma verdade absoluta, com impactos devastadores para a humanidade. Ainda, afirmam que a imprensa brasileira, ao dar um tratamento sobre o aquecimento global como uma verdade irrevogável, o debate fica empobrecido, pois nega-se a existência de um pensamento contrário à hipótese antropogênica como causa principal das mudanças climáticas. Corroborando a constatação, o estudo de Carneiro e Toniolo (2012) analisaram 676 notícias, das quais apenas 7 (1,03\%) apresentaram opiniões contrárias ao alegado consenso.

Recente estudo de Dayrell e Urry (2015) estabelece uma relação entre o grau de preocupação do brasileiro com a quantidade de notícias sobre mudanças climáticas. Em 2002, apenas um quinto dos brasileiros expressaram preocupação com as questões ambientais. Em 2007, o percentual de brasileiros que consideravam as questões ambientais como uma grande ameaça mundial subiu acentuadamente, atingindo $49 \%$. Em 2009, os brasileiros foram os mais preocupados com a mudança climática, enquanto o ceticismo era quase inexistente: $94 \%$ dos brasileiros afirmaram que o aquecimento global é uma ameaça muito ou pouco graves.

De acordo com ANDI (2009), a mudança na opinião pública está fortemente relacionada com o aumento exponencial do número de reportagens que, de uma forma ou de outra, transmitem a tese de que a mudança climática está acontecendo e que é uma questão de preocupação significativa. Na geração e reprodução da opinião de que as emissões antropogênicas de gases de efeito estufa que são fundamentais, a mídia brasileira parece desempenhar um papel central.

Painter (2011) e Painter e Ashe (2012) relatam a quase inexistência de ceticismo sobre as alterações climáticas na mídia brasileira. No Brasil, a quantidade de notícias que continham vozes de ceticismo climático foi a mais baixa (1\% em 2007 e 3\% em 2009/2010) em relação a outros cinco países analisados. A porcentagem de ceticismo na mídia, em 2009, foi de 34\% nos EUA, 17\% no Reino Unido, 7\% na China e 6\% na França e na Índia.

\section{DA IGNORÂNCIA À LITERACIA, UMA GUINADA POSSÍVEL}

A falta de conhecimento (ou ignorância) e de reflexão crítica criou medos irracionais perante as mudanças climáticas. Esses medos precisam ser superados e resolvidos. Se é verdadeira a premissa de que o medo é gerado pela ignorância e 
pelo desconhecido, então o oposto deve ser verdadeiro: conhecer para não temer. Assim, o conhecimento e o esclarecimento geram menos apreensão e mais segurança na avaliação crítica de informações apresentadas propositadamente com teor preocupante. Nesse sentido, a primeira parte da solução para o problema da ignorância, portanto, é fornecer informações precisas ao público, tanto no ensino formal (instituições de ensino) quanto no ensino informal (meios de comunicação).

Uma campanha robusta para promover a literacia científica do clima por meio da educação formal e informal, com amplo uso dos canais de comunicação, pode ajudar a esclarecer as confusões climáticas, abordando as lacunas sistêmicas cognitivas e os equívocos comuns na percepção das pessoas. Os desafios são significativos. A abordagem dos equívocos exigirá, primeiro, uma consciência dos equívocos, ferramentas, modelos mentais eficazes e estratégias para identificá-los e superá-los, uma formação adequada e desenvolvimento profissional dos educadores, e o quadro conceitual e recursos de alta qualidade para informar e envolver os alunos. Evitando representações que levam a equívocos, novos recursos estão se tornando mais acessíveis e sofisticados para explicar conceitos básicos do clima, como, por exemplo, recursos didáticos multimídia e visualizações que empregam animações e permitem explicar os conceitos de uma maneira nova (MCCAFFREY; BUHR, 2008).

Para ensinar a ciência do clima de forma eficaz e abordar suas próprias lacunas de conhecimento e equívocos, os professores devem ser devidamente treinados por meio do desenvolvimento prévio e durante o desempenho profissional. Assim, deve-se fornecer ferramentas de aprendizagem precisas, recursos e fontes de referências atualizadas que identifiquem especificamente os equívocos comuns e as deficiências cognitivas dos alunos. Ao mesmo tempo, os cientistas estão aprendendo lentamente a tornar-se mais eficazes em comunicar as complexidades da ciência para o público não-técnico, facilitando a reprodução das informações pelos professores e pelas meios de comunicação (MCCAFFREY; BUHR, 2008).

Um grande desafio consiste em fornecer ao público informações, documentos e referências que ajudem a romper o analfabetismo climático de décadas de equívocos, lacunas pedagógicas e confusões do público com relação aos conceitos científicos do clima. Nesse sentido, em um esforço singelo e com o intuito de fornecer uma visão mais equilibrada e sensata na discussão das mudanças climáticas, Oliveira 
e Vecchia (2013) ${ }^{11}$ apresentam um texto didático e explicativo, compatível com os níveis médio, técnico e superior.

\subsection{Raciocínio científico e literacia climática}

Raciocinar sobre questões sócio-científicas requer que os indivíduos enxerguem além do mero raciocínio lógico e comecem a incorporar outras formas de raciocínio que lhes permitam considerar questões complexas, como as mudanças climáticas. Esse tipo de raciocínio envolve conceituar a complexidade inerente das questões, impedindo o raciocínio simples e linear de causa e efeito, bem como construir e avaliar argumentos construídos a partir de várias perspectivas em dilemas duvidosos. Com base nessa perspectiva, Liu, Varma e Roehrig (2014) caracterizaram quatro dimensões gerais do raciocínio sócio-científico:

1. Reconhecer a complexidade inerente de questões sócio-científicas;

2. Analisar estas questões a partir de perspectivas múltiplas;

3. Considerar que estas questões estão sujeitas a investigações contínuas; e

4. Exibir ceticismo quando se apresenta informações potencialmente tendenciosas.

$\mathrm{Na}$ educação da mudança climática, o raciocínio com analogias é especialmente benéfico em promover o desenvolvimento da literacia climática. Questões de mudanças climáticas globais são inerentemente abstratas e a natureza da mudança climática global é praticamente impossível de detectar e experimentar. Assim, a aquisição de conhecimento sobre a mudança climática é particularmente difícil, e a maioria das pessoas só entendem a mudança climática global na medida em que ela afeta sua vida cotidiana (LIU; VARMA; ROEHRIG, 2014).

A argumentação deve ser um elemento fundamental na educação da mudança climática. $O$ público está constantemente sujeito a uma multidão de debates sobre a aquecimento global. Diante de todas as perspectivas e as discussões em torno deles, os indivíduos devem ser capazes de raciocinar criticamente sobre a

\footnotetext{
${ }^{11}$ Considerando que, em diversos trabalhos científicos e notícias, um volume imenso de informações é dedicado à influência humana no clima, muitas vezes omitindo ou menosprezando as causas naturais, Oliveira e Vecchia (2013) apresentam dados mais ponderados entre as causas (naturais e antropogênicas) e os efeitos das mudanças climáticas, além de conceitos básicos sobre balanço de radiação, forçamentos radiativos, gases de efeito estufa, aerossóis, emissões solares, parâmetros orbitais terrestres, atividades vulcânicas, entre outros.
} 
informação que recebem, e precisam estar aptos na geração de argumentos sólidos para apoiar ou refutar alegações. Além disso, ensinar os alunos a raciocinar, discutir, e pensar criticamente irá melhorar a sua aprendizagem conceitual (LIU; VARMA; ROEHRIG, 2014).

Melhorar a literacia do público em relação ao clima é uma questão interdisciplinar, exigindo dos cientistas e educadores uma colaboração para sintetizar e compartilhar o conhecimento científico de um sistema imensamente complexo que engloba o clima, a economia e a sociedade. Com o crescente número de descobertas científicas sobre a mudança climática, existe uma lacuna crescente entre 0 conhecimento científico e a compreensão pública sobre essa questão. Como muitos fatores podem exacerbar essa diferença, tais como a complexidade da ciência do clima e orientações ideológicas pessoais, há uma necessidade imediata para a discussão de processos cognitivos que podem promover a compreensão da complexa ciência do clima. (LIU; VARMA; ROEHRIG, 2014).

Quanto aos alunos, segundo Liu, Varma e Roehrig (2014), eles precisam ser explicitamente ensinados como ser céticos, como identificar tendências, parcialidades e manipulações em afirmações científicas, e como refletir criticamente sobre como as descobertas científicas são divulgadas. Um dos objetivos educacionais mais críticos é que os alunos aprendam sobre como questões sócio-científicas são tratadas e avaliadas dentro da sociedade, e que sejam capazes de agir como cidadãos responsáveis no futuro. Incorporar o raciocínio científico na educação sobre mudança climática irá ajudar a cumprir essa meta. É essencial que o público em geral reconheça a relevância do raciocínio científico e o seu impacto na alfabetização climática. E para facilitar a assimilação desse raciocínio, é fundamental que os cientistas e educadores colaborem estreitamente para fornecer mais informação científica sobre a mudança climática global, utilizando uma linguagem que seja compatível com os processos cognitivos do público, e incentivando mais discussões das mudanças climáticas globais na sociedade e nas escolas.

Uma sociedade cientificamente alfabetizada (não proficiente, apenas alfabetizada) é essencial para o discurso racional e o julgamento consciente de questões amplas, em um milênio dominado pela ciência e tecnologia e repleto de questões ambientais e sócio-científicas importantes, como é o caso das mudanças climáticas. 


\section{CONSIDERAÇÕES FINAIS}

A proposta do heliocentrismo por Nicolau Copérnico há mais de 500 anos atrás foi precursora da astronomia moderna e representa uma das mais importantes descobertas científicas de todos os tempos. O desconhecimento do movimento da Terra ao redor do Sol aponta níveis deploráveis de literacia científica entre estudantes e adultos, ao tal ponto que, com base nos resultados gerais de enquetes em diversos países, uma parcela significativa dos entrevistados é considerada analfabeta científica.

A partir dos dados levantados e apresentados neste trabalho, percebe-se que as pessoas possuem grande preocupação com as questões climáticas, mas ainda carecem de uma base conceitual científica adequada sobre temas relativamente simples. $O$ analfabetismo científico é reflexo direto da qualidade e condições gerais de educação das pessoas. Os lamentáveis resultados obtidos com base na opinião dos adultos reproduzem as falhas educacionais presentes desde a infância e juventude.

Os números de diferentes fontes comprovam aquela percepção que incomoda todos os brasileiros: a educação no Brasil é péssima. $\mathrm{E}$ a triste realidade não permite utilizar qualquer outra palavra com um tom mais brando, pois a situação é simplesmente angustiante. O Brasil pode ter apresentado melhorias, tímidas, e pode estar rumo a uma situação melhor. Entretanto, ainda está longe de uma condição desejável e respeitável. São urgentes mudanças drásticas, colocadas em prática com muita vontade e afinco, capazes de transformar o enorme potencial do país em uma concreta e merecida posição de destaque e de referência em educação de qualidade.

A combinação de uma população pessimamente educada, analfabeta cientificamente, profundamente desconhecedora de conceitos das mudanças climáticas e uma mídia sensacionalista e alarmista quanto aos efeitos do aquecimento global, fatalmente resultou em uma síndrome social, ou "eco-ansiedade". Diante da apresentação contínua de histórias assustadoras sobre o aquecimento global na mídia popular, naturalmente (ou forçosamente) o público tem manifestado diferentes níveis de ansiedade, ficando preocupado, amedrontado, depressivo e, muitas vezes, desnecessariamente apavorado.

O aspecto controverso da discussão da influência humana no recente aumento da temperatura média global acrescenta ainda mais dificuldades, confusões 
e equívocos sobre complexo tema das mudanças climáticas. Somente com a riqueza de informações, algumas vezes contraditórias, pode-se desenvolver uma visão mais ampla e clara dos fatores e componentes climáticos. Com a plena compreensão de seu funcionamento, será possível estabelecer um julgamento confiável sobre a magnitude do impacto das atividades humanas no clima da Terra.

A literacia científica do clima, por sua vez, possui uma dificuldade inerente, e aprimorar a situação geral é um problema muito grande para ser resolvido por qualquer agência ou esforço individual. Para resolver os problemas que resultam do analfabetismo em relação à ciência, é fundamental que, primeiro, sejam superadas as falhas educacionais principalmente nos níveis fundamental e médio. Segundo, somente com o melhoria cognitiva e aumento da capacidade intelectual será possível uma maior habilidade de abstração e entendimento de complicados e interligados conceitos físicos, químicos e biológicos associados à ciência do clima. Como precursores desse processo, três grandes profissionais difusores de informação possuem papéis principais: os jornalistas, os cientistas e os professores.

Sem o conhecimento adequado em climatologia, os jornalistas, seus leitores, os professores e os seus alunos são forçados a usar meios indiretos para avaliar a gravidade do aquecimento global, como os depoimentos de cientistas do clima. Se os jornalistas e professores souberem mais sobre ciência, então suas notícias e aulas serão mais precisas e então, talvez, o público e os alunos consigam entender mais sobre questões sobre as alterações climáticas. Mas, mesmo para um jornalista ou professor, cientificamente alfabetizado, saber identificar os verdadeiros mecanismos de causas e efeitos da mudança climática pode representar uma tarefa nada fácil.

No tocante às divulgação de assuntos relacionados às mudanças climáticas, é imperativa a necessidade da apresentação dos vários pontos de vista existentes. A norma jornalística do relato equilibrado é amplamente considerada um dos pilares tradicionais do bom jornalismo. Com isenção de conflito de interesses, o balanço almeja a neutralidade, exigindo dos repórteres a apresentação dos pontos de vista dos representantes das partes em conflito em qualquer disputa significativa, proporcionando a ambos os lados uma atenção aproximadamente igual e equilibrada $^{12}$.

\footnotetext{
${ }^{12} \mathrm{Na}$ abordagem de temas polêmicos, indica-se um sucinto mas eficiente material, "Cobrindo controvérsias", parte de um curso de Jornalismo Científico, disponível em <http://www.wfsj.org/course/pt/L6/L6P00.html>. Acesso em: 07 jun. 2015.
} 
Aos professores, Tenreiro-Vieira e Vieira (2013) exprimem que:

(...) não é expectável que os futuros professores fomentem a literacia científica e matemática crítica dos seus alunos se eles próprios não se sentirem confiantes, incitados e desejosos por alcançar níveis sucessivamente mais elevados de literacia científica e matemática. A questão da formação de professores assume, pois, importância crucial, porquanto é dos professores e, em particular, da sua formação que depende grandemente a promoção da literacia matemática e da literacia científica crítica dos seus alunos.

Cabe destacar que a alfabetização científica não é somente uma medida da quantidade do conhecimento, mas principalmente representa uma medida da habilidade em coletar informações sobre um determinado assunto, juntamente com a capacidade de distinguir fontes confiáveis de não-confiáveis. Nem todo mundo está preocupado com a promoção da literacia científica, pois há muitas agendas movidas por interesses sociais, políticos e comerciais. Esse fato traz implicações sérias para a quantidade e a qualidade da informação disponível hoje na Internet, uma fonte facilmente acessível e cada vez mais utilizada. Considerando que a Internet tem exponencialmente oferecido cada vez mais informação ao público, o discernimento de fontes confiáveis é uma habilidade essencial para qualquer pessoa alfabetizada em ciência.

$O$ retrato do aquecimento global tem se revelado demasiadamente intricado para a maioria dos difusores de informação, os jornalistas na mídia e os professores nas escolas. Nesse sentido, os cientistas também desempenham um papel fundamental na divulgação científica. Os cientistas muitas vezes subestimam a complexidade envolvida na popularização da ciência. Por exemplo, para apreciar a complexidade do sistema climático, é importante compreender as interligações entre a atmosfera, hidrosfera, criosfera, litosfera e biosfera. A compreensão plena dessas interfaces exige uma abordagem com pensamento científico e sistemático, um modus operandi muito bem internalizado e praticado pelos cientistas. Porém, cabe aos cientistas proporcionarem a tradução e simplificação dos conceitos científicos, utilizando-se de recursos didáticos modernos, em especial aqueles baseados em multimídias digitais e ricamente visuais.

Juntos, os geradores e promotores da informação, cientistas, jornalistas e professores, possuem um grande desafio pela frente, o de criar uma "consciência 
pública da ciência", a qual é sumarizada com muita propriedade por Vogt, Cerqueira e Kanashiro (2008):

Não cabe à divulgação científica apenas levar a informação, mas também atuar de modo a produzir as condições de formação crítica do cidadão em relação à ciência. Não só cabe à divulgação a aquisição de conhecimento e informação, mas a produção de uma reflexão relativa ao papel da ciência, sua função na sociedade, as tomadas de decisão correlatas, fomentos, aos apoios da ciência, seu próprio destino, suas prioridades e assim por diante. Isso vai além da atitude inicial, na qual o cientista era o sábio, o cidadão era o ignorante e o jornalista científico ou divulgador da ciência era o construtor da ponte entre essas figuras, de maneira a suprir o tal déficit de informação. (...) o que está sendo enfatizado não é só a aquisição da informação, a possibilidade de acesso à informação, mas a formação do cidadão no sentido em que ele possa ter opiniões e uma visão crítica de todo o processo envolvido na produção do conhecimento científico com sua circulação e assim por diante. Esse é um conceito relacionado à cultura científica que modifica os modos de se fazer e pensar a própria divulgação.

As geociências, a ciência ambiental e as ciências do clima continuam gerando conhecimento abrangente e complexo. O desafio para a educação não consiste apenas em produzir mais e melhores cientistas ambientais, mas também deve favorecer a formação de cidadãos informados e motivados, que sejam capazes de compreender, interpretar e tomar decisões com base em evidências e teorias científicas sofisticadas. Portanto, é necessário que haja uma ênfase imediata sobre o desenvolvimento de habilidades de raciocínio e de reflexão crítica adequadas para reforçar a alfabetização científica e climática, a fim de corrigir as falhas atuais e evitar equívocos adicionais futuros.

\section{REFERÊNCIAS}

ANDI. Climate change in the Brazilian news media: a comparative analysis of 50 newspapers. 2009. Disponível em: <http://www.mudancasclimaticas.andi.org.br/content/climate-change-brazilian-newsmedia>. Acesso em 07 jun. 2015.

ANELLI, C. Scientific Literacy: What Is It, Are We Teaching It, and Does It Matter? American Entomologist, Annapolis, v. 57, n. 4, p. 235-243, 2011.

ASAYAMA, R. Catastrophism toward 'opening up' or 'closing down'? Going beyond the apocalyptic future and geoengineering. Current Sociology, v. 63, n. 1., p. 89-93, 2015.

BAPTISTA, G.M.M. Aquecimento Global: Ciência ou Religião? 1 ed. Brasília: Hinterlândia Editorial, 2009. 186 p.

BRASIL. Ministério da Ciência, Tecnologia e Inovação. Percepção pública da ciência e tecnologia. Brasília: Ministério da Ciência, Tecnologia e Inovação. 2007. Disponível em: <http://www.mct.gov.br/upd_blob/0227/227677.pdf>. Acesso em: 07 jun. 2015.

BRASIL. Ministério da Ciência, Tecnologia e Inovação. Percepção pública da ciência e tecnologia no Brasil: resultados da enquete de 2010. Brasília: Ministério da Ciência, Tecnologia e Inovação. 2010. Disponível em: <http://www.mct.gov.br/upd_blob/0214/214770.pdf>. Acesso em: 07 jun. 2015.

CARNEIRO, C.D.R; TONIOLO, J.C. A Terra 'quente' na imprensa: confiabilidade de notícias sobre 
aquecimento global. História, Ciências, Saúde - Manguinhos, Rio de Janeiro, v. 19, n. 2, p. 369-389, abr.-jun., 2012.

CASTELFRANCHI, Y. et al. As opiniões dos brasileiros sobre ciência e tecnologia: o 'paradoxo' da relação entre informação e atitudes. História, Ciências, Saúde - Manguinhos, Rio de Janeiro, v. 20, supl., p.1163-1183, nov. 2013.

DAYRELL, C.; URRY, J. Mediating climate politics: The surprising case of Brazil. European Journal of Social Theory, 17 pp., 2015. (Publicado online, antes de impressão, em 22 abr. 2015. doi:10.1177/1368431015579962)

DOHERTY, T.J.; CLAYTON, S. The Psychological Impacts of Global Climate Change. American Psychologist, v. 66, n. 4, p. 265-276, mai./jun., 2011.

DÖRRIES, M. Climate catastrophes and fear. Wiley Interdisciplinary Reviews: Climate Change, v. 1, n. 6, nov./dez., 2010.

ESTADÃO ONLINE. Pais atiram em bebê por desespero ante o aquecimento global. 02 mar. 2010. Disponível em: <http://sustentabilidade.estadao.com.br/noticias/geral,pais-atiram-em-bebe-pordesespero-ante-o-aquecimento-global,518277>. Acesso em: 07 jun. 2015.

FELÍCIO, R.A. "Mudanças Climáticas" e "Aquecimento Global" - Nova Formatação e Paradigma para o Pensamento Contemporâneo? Ciência e Natura, Santa Maria, v. 36, ed. especial, p. 257-266, 2014.

FELÍCIO, R.A.; ONÇA, D.S. "Aquecimento global", "mudanças climáticas" e "caos ambiental" justificando o falso "desenvolvimento sustentável": a Teoria da Tríade. Fórum Ambiental da Alta Paulista, v. VI, p. 569-590, 2010.

FRITZE, J.G. et al. Hope, despair and transformation: Climate change and the promotion of mental health and wellbeing. International Journal of Mental Health Systems, v. 2, n. 13, set. 2008.

GILLESPIE, S. Climate change and psyche: Conversations with and through dreams. International Journal of Multiple Research Approaches, v. 7, n. 3, p. 343-354, 2013.

GOW, K.S.K. Do concerns about climate change lead to distress? International Journal of Climate Change Strategies and Management, v. 2, n. 4, p. 362-379, 2010.

HÖIJER, B. Emotional anchoring and objectification in the media reporting on climate change. Public Understanding of Science, v. 19, n. 6, p. 717-731, 2010.

HULME, M. Newspaper scare headlines can be counter-productive. Nature, v. 445, n. 22, p. 818, fev. 2007.

LI, S.S. Fear Appeals and College Students' Attitudes and Behavioral Intentions Toward Global Warming. The Journal of Environmental Education, v. 45, n. 4, p. 243-257, 2014.

LINO, L.G. A fraude do aquecimento global: como um fenômeno natural foi convertido numa falsa emergência mundial. 2 ed. Rio de Janeiro: Capax Dei, 2010.

LIU, S.; VARMA, K.; ROEHRIG, G. Climate Literacy and Scientific Reasoning. In: DALBOTTEN, D.; ROEHRIG, G.; HAMILTON, P. Future Earth - Advancing Civic Understanding of the Anthropocene, Hoboken: John Wiley \& Sons, Inc. 2014.

MARUYAMA, S. Aquecimento global? Tradução SUGUIO, K. São Paulo: Oficina de Textos, 2009. 125 p. Tradução de: Do not be taken in by the global warming theory.

MCCAFFREY, M.S.; BUHR, S.M. Clarifying Climate Confusion: Addressing Systemic Holes, Cognitive Gaps, and Misconceptions Through Climate Literacy. Physical Geography, v. 29, n. 6, p. 512-528, 2008.

MILLER, J.D. The measurement of civic scientific literacy. Public Understanding of Science, v. 7, n. 3, p. 203-223, jul. 1998.

NATIONAL SCIENCE BOARD. Science and Engineering Indicators 2014. Arlington VA: National Science Foundation, 2014. Disponível em:

<http://www.nsf.gov/statistics/seind14/content/etc/nsb1401.pdf>. Acesso em: 07 jun. 2015.

O'NEILL, S.; NICHOLSON-COLE, S. "Fear Won't Do It". Promoting Positive Engagement With Climate Change Through Visual and Iconic Representations. Science Communication, v. 30, n. 3, p. 355-379, mar. 2009. 
OCDE. Green at Fifteen? How 15 -year-olds perform in environmental science and geoscience in PISA 2006. OCDE, 2009. Disponível em: $<$ http://browse.oecdbookshop.org/oecd/pdfs/free/9809071e.pdf>. Acesso em: 07 jun. 2015.

OCDE. BRAZIL - Country Note - Results from PISA 2012. OCDE, 2013. Disponível em: <http://www.oecd.org/pisa/keyfindings/PISA-2012-results-brazil.pdf>. Acesso em: 07 jun. 2015.

OCDE. PISA 2012 Results in Focus. What 15-year-olds know and what they can do with what they know. OCDE, 2014. Disponível em: <http://www.oecd.org/pisa/keyfindings/pisa-2012-resultsoverview.pdf>. Acesso em: 07 jun. 2015.

OCDE. About PISA. OCDE, 2015. Disponível em: <http://www.oecd.org/pisa/aboutpisa/>. Acesso em: 07 jun. 2015.

OLIVEIRA, M.J. Incertezas associadas à temperatura do ar no contexto das mudanças climáticas: determinação das causas e efeitos de heterogeneidades e discussão das implicações práticas. 2010. 419p. Dissertação (Mestrado-Programa de Pós-Graduação em Ciências da Engenharia Ambiental) - Escola de Engenharia de São Carlos, Universidade de São Paulo, São Carlos, 2010. Disponível em:

<http://www.teses.usp.br/teses/disponiveis/18/18139/tde-25042011-095947/pt-br.php>. Acesso em: 07 jun. 2015.

OLIVEIRA, M.J.; VECCHIA, F.A.S. A Controvérsia das Mudanças Climáticas e do Aquecimento Global Antropogênico: Consenso Científico ou Interesse Político? Fórum Ambiental da Alta Paulista, v. V, p. 946-962, 2009.

OLIVEIRA, M.J.; VECCHIA, F.A.S. Mudanças Climáticas. In: CALIJURI, Maria do Carmo Calijuri; CUNHA, Davi Gasparini Fernandes. (Org.). Engenharia Ambiental: Conceitos, Tecnologia e Gestão. $1^{\underline{a}}$ ed. Rio de Janeiro: Elsevier, 2013, v. 1, p. 367-400.

ONÇA, D.S. Curvar-se diante do existente: 0 apelo às mudanças climáticas pela preservação ambiental. 2007. Dissertação (Mestrado em Geografia Física) - Faculdade de Filosofia, Letras e Ciências Humanas, Universidade de São Paulo, São Paulo, 2007.

ONÇA, D.S. “Quando o sol brilha, eles fogem para a sombra...”: a ideologia do aquecimento global. 2011. Tese (Doutorado em Geografia Física) - Faculdade de Filosofia, Letras e Ciências Humanas, Universidade de São Paulo, São Paulo, 2011.

PAINTER, J. Poles Apart: The International Reporting of Climate Scepticism. Oxford: Reuters Institute for the Study of Journalism. 2011.

PAINTER, J; ASHE, T. A cross-national comparison of the presence of climate scepticism in the print media in six countries, 2007-10. Environmental Research Letters, v. 7, n. 4, 8 pp., 2012.

PEW RESEARCH CENTER. Climate Change and Financial Instability Seen as Top Global Threats. Pew Research Center. jun. 2013. Disponível em: <http://www.pewglobal.org/files/2013/06/Pew-

Research-Center-Global-Attitudes-Project-Global-Threats-Report-FINAL-June-24-20131.pdf>. Acesso em: 07 jun. 2015.

SCHULTE, K.M. Scientific consensus on climate change? Energy \& Environment, v. 19, n. 2, p. 281286, 2008.

SHEPARDSON, D.P. et al. Students' conceptions about the greenhouse effect, global warming, and climate change. Climatic Change, v. 104, n. 3-4, p. 481-507, 2011.

SOMERVILLE, R.C.J. How much should the public know about climate science? Climatic Change, v. 104, n. 3-4, p. 509-514, 2011.

STERN, P.C. Fear and hope in climate messages. Nature Climate Change, v. 2, n. 8, p. 572-573, ago. 2012.

TENREIRO-VIEIRA, C.; VIEIRA, R.M. Literacia e pensamento crítico: um referencial para a educação em ciências e em matemática. Revista Brasileira de Educação, Rio de Janeiro, v. 18, n. 52, p. 163242, jan.-mar. 2013.

THEISSEN, K.M. What Do U.S. Students Know About Climate Change? EOS, Transactions, American Geophysical Union, v. 92, n. 51, p. 477-488, dez. 2011.

USGCRP. Climate Literacy. The Essential Principles of Climate Science. U.S. Global Change Research Program (USGCRP). Climate Change Science Program. Second version, 2009. Disponível 
em: <http://downloads.globalchange.gov/Literacy/climate_literacy_lowres_english.pdf>. Acesso em: 07 jun. 2015.

VOGT, C.; CERQUEIRA, N.; KANASHIRO, M. Divulgação e cultura científica. ComCiência [online]. n. 100, 4 pp., 2008.

ZANGALLI JUNIOR, P.C.; SANT'ANNA NETO, J.L. O discurso das mudanças climáticas a influência dos agentes sociais no aquecimento global. Geografia em Atos, v. 2, n. 11, p. 1-15, jul./dez., 2011. 